\title{
Pricing Problem in the E-Commerce Low-Carbon Supply Chain under Asymmetric Fairness Preferences
}

\author{
Lei Song $(D$, Qi Xin, and Cheng-Min Wu \\ Department of Electronic Commerce, Fujian Jiangxia University, Fuzhou, China \\ Correspondence should be addressed to Lei Song; 8949581@qq.com
}

Received 19 December 2021; Revised 1 February 2022; Accepted 8 February 2022; Published 3 March 2022

Academic Editor: Yong He

Copyright (c) 2022 Lei Song et al. This is an open access article distributed under the Creative Commons Attribution License, which permits unrestricted use, distribution, and reproduction in any medium, provided the original work is properly cited.

\begin{abstract}
Given the different fairness preferences of online retailers and their investment in emission reduction and revenue sharing with manufacturers, an e-commerce low-carbon supply chain decision model was established using Stackelberg game theory under three circumstances: no fairness preference, symmetric fairness preferences, and asymmetric fairness preferences. Results reveal that the asymmetric fairness preference behaviors of online retailers weaken the manufacturers' profits, where the online retailer's utility is negatively correlated with its asymmetric fairness preference coefficient. The real fairness preference coefficient of the online retailer estimated by the manufacturer is negatively correlated with the manufacturer's wholesale price and carbon emission reduction. The revenue sharing proportion of the manufacturer presents a positive correlation with its wholesale price but shows no correlation with the retail price, the green degree, or the supply chain profit. Within a feasible region, the proportion of the online retailer's investment in emission reduction is positively correlated with the manufacturer's profit, the online retailer's utility, the total utility of the supply chain, the carbon emission reduction, the product's retail price, and the product's wholesale price.
\end{abstract}

\section{Introduction}

With the sustainable economic development, resources have been consumed at an ever-increasing speed, triggering problems, such as the surge of $\mathrm{CO}_{2}$ emission and the continuous aggravation of the surrounding environment [1]. Therefore, many governments have enacted relevant laws and regulations to restrict and reduce carbon emissions [2-4]. Meanwhile, consumers have started to consciously select low-carbon products with the gradual transformation of consumer demand into low-carbon products because of their continuously growing environmental awareness [5]. For example, a study on consumers shows that approximately $80 \%$ of American consumers would buy low-carbon products even at extra cost [6]. Under this background, to improve their competitiveness and social image, members of the supply chain are committed to the transformation from a traditional supply chain to a low-carbon supply chain. This transformation will directly impact all members of the supply chain. In particular, to reduce the carbon emissions in the production process, manufacturers have to transform and upgrade their production equipment and thus bear considerable cost pressure. To solve the low-carbon development problem of the supply chain and improve the enthusiasm of supply chain enterprises for emission reduction, the upstream and downstream enterprises of the supply chain can form a community of interests through mutual investment and cooperation. For example, Honda (Japan) has a $28 \%$ stake in its component suppliers [7], and Gree (China) dealers invested in Gree, holding 10\% of its shares.

In recent years, e-commerce has accounted for an everincreasing proportion of the economy, and online retailers have become the main force of the retail industry [8]. In the traditional supply chain, manufacturers dominate the consumer demands; that is, online retailers sell whatever is produced by manufacturers. However, as big data technology continues to mature, the integrated development of e-commerce and big data is becoming an essential development trend of the e-commerce industry. With diversified functions, like advanced data analysis, data reserves, and 
data prediction, big data technology can help e-commerce enterprises rapidly and accurately master market information and determine the consumer demands. Online retailers have gained the best understanding of the consumer demands in the supply chain. As the optimal operation strategy, online retailers, which are typical asset-light enterprises, must seek for the corresponding original equipment manufacturers (OEMs) after quickly acquiring accurate market information under the driving force of data. For example, Xiaomi (China) exploits its brand influence and perfect sales channels to find competitive partners or teams to invest in segments and jointly design and develop products with for its two brands, Xiaomi and Mijia. As the low-carbon preferences of consumers are strengthened, the consumer demands have gradually turned to the low-carbon products in the market. To meet the low-carbon requirements, OEMs must bear the high costs induced by carbon emission reduction. Under this circumstance, online retailers, who are important members of the e-commerce lowcarbon supply chain, are required to accordingly share in the carbon emission reduction cost. Meanwhile, manufacturers can consider revenue sharing.

Previous research regarding the decision problem of supply chains has been mostly based on the complete rationality hypothesis of subjects, while the present research in this field focuses on the irrational behavioral factors of subjects in the supply chain, among which the behavioral factor-fairness preference-has aroused great attention. As the cooperative emission reduction in the e-commerce lowcarbon supply chain is deepened, manufacturers are increasingly coupled with online retailers, and both are not only concerned about their revenues but also pay attention to the revenue status of other members, showing fairness preferences. However, the fairness preferences of supply chain members are considered private information. In reality, e-commerce supply chain members are usually reluctant to disclose such private information to acquire more benefits, thus forming fairness preferences with information asymmetry, which may affect the pricing decision and performance of the e-commerce low-carbon supply chain.

As low-carbon economy has become a development trend, the investment of online retailers on carbon emission reduction and revenue sharing with manufacturers contributes to the sustainable development of the e-commerce low-carbon supply chain. However, this supply chain certainly has asymmetric fairness preferences because retailers and manufacturers cannot be completely rational in reality and their preference information is private. In such a supply chain environment, making correct pricing decisions for low-carbon products is a realistic and urgent issue.

Thus, this paper builds an e-commerce low-carbon supply chain model under fairness preference and considers the investment of online retailers in emissions reduction and the revenue sharing of manufacturers. On the basis of optimization theory and the Stackelberg game, three different scenarios-the no fairness, symmetric fairness, and asymmetric fairness preferences of online retailers-were analyzed. On this basis, the pricing problem in the e-commerce low-carbon supply chain under the asymmetric fairness preference was explored. Given that the research regarding the symmetric fairness preference is mostly based on ideal conditions, this research was conducted under the asymmetric fairness preference, which is highly consistent with reality and thus has a high practical and effective guiding significance to the operation of the e-commerce low-carbon supply chain. The study questions to be answered are as follows:

(1) Under three different scenarios, namely, the no fairness, symmetric fairness, and asymmetric fairness preferences of online retailers, what are the differences in the utility, price decision, and carbon emission reduction of the e-commerce low-carbon supply chain?

(2) Considering the asymmetric fairness preference of online retailers, how does the investment of online retailers affect the utility, price decision, and carbon emission reduction of the e-commerce low-carbon supply chain?

(3) Considering the asymmetric fairness preference of online retailers, how does the revenue sharing of manufacturers affect the utility, price decision, and carbon emission reduction of the e-commerce lowcarbon supply chain?

The innovations of this paper are as follows:

(1) Compared with the existing literature, this paper constructs an e-commerce low-carbon supply chain model considering the investment of online retailers in emissions reduction and the revenue sharing of manufacturers under the fairness preference, making the e-commerce low-carbon supply chain pricing decision model closer to reality. Furthermore, the pricing decision-making under different scenarios is compared and analyzed.

(2) Most of the previous studies considered the symmetric fairness preference. To make the model closer to reality and further enhance the ability of the research conclusions to provide guidance, this paper considers the asymmetric fairness preference of online retailers.

The rest of this paper is organized as follows. In Section 2 , a literature review of related research subjects is presented. In Section 3, the models and symbols are described and explained. In Section 4, the decision models of the lowcarbon e-commerce supply chain under different circumstances are constructed and solved. In Section 5, a numerical calculation example is analyzed, and some research conclusions are drawn by combining the equilibrium solutions obtained in Section 4. Finally, the conclusions and limitations are summarized in Section 6.

\section{Literature Review}

This study is related to three research streams in the literature: the influences of the subjects' behavioral preferences on the decisions in the low-carbon supply chain, the cost 
sharing of carbon emission reduction among supply chain enterprises, and the fairness preferences on the decisions in the supply chain.

2.1. Influences of Subjects' Behavioral Preferences on the Decisions in the Low-Carbon Supply Chain. As mentioned in the Introduction, the low-carbon supply chain has attracted increasing attention with the ever-aggravated ecoenvironmental problems. Fruitful results have been achieved in the research regarding the influences of subjects' behavioral preferences on the optimal decisions in the low-carbon supply chain.

Zhang et al. [9] explored how the strategy formulation in the green supply chain is influenced by fairness preferences and found that if any party between the manufacturer and the retailer has fairness preferences, the profit of the other party will be negatively affected by such a party. Meanwhile, the fairness preference of any party will also negatively affect the profits of the entire green supply chain but increase its own profit ratio in the overall profits of the green supply chain. In contrast, the wholesale price and degree of environmental protection of products will drop substantially due to the fairness preferences of retailers, and the overall profit status of the green supply chain will become poor owing to the fairness preferences of manufacturers. Wang et al. [10] investigated the retailers-dominated decision-making and coordination of the low-carbon supply chain, which consists of dominant retailers and medium and small-sized manufacturers under altruistic preferences. The results show that altruistic preference is conducive to improving the profit and system efficiency of medium and small-sized manufacturers but reduces the profits of retailers. Sun et al. [11] explored the influence of consumers' green preference on carbon emission strategies and discovered that consumers' green preferences can drive manufacturers toward carbon emission reduction, while the commitment level of suppliers is unrelated to the low-carbon preferences of consumers. Fan et al. [12] probed the influences of retailers' altruistic preferences and consumers' low-carbon preferences on the complex nonlinear dynamic behaviors of two models, and their results indicate that consumers' low-carbon preferences and retailers' altruistic preferences will decrease the stability region of the system. In static and dynamic game models, retailers' altruistic preferences have a positive influence on manufacturers but negative influence on themselves and the entire supply chain. Meng et al. [13] investigated how the pricing policies of the supply chain were formulated under the channel and green preference behaviors of consumers, and their results indicate that the green preferences of consumers can increase the demands for green products, while the channel preferences of consumers will reduce such demands. Du et al. [14] studied the influence of consumers' low-carbon preference on the supply chain and discovered that these preferences are increased by channel profit and emission reduction under specific circumstances. Li et and Zhao [15] explored the supply chain coordination problem of the different contracts provided by manufacturers to retailers with fairness preferences under the low-carbon environment and found that, in the event of distribution justice, the wholesale price contract can coordinate the supply chain under specific conditions, and the supply chain can still be coordinated only if the equivalence of the revenue sharing and repurchase contracts is unchanged. Li et al. [16] probed the low-carbon double-channel supply chain with the fairness concerns of both manufacturers and retailers, where manufacturers consider the carbon emission reduction and retailers provide sales services in the traditional channels. Their results show that the fairness concerns of retailers can weaken the stability of the supply chain system more than those of manufacturers. Zou et al. [17] studied the influence of the fairness problem on the sustainable low-carbon supply chain with carbon quota policies. Their results indicate that the fairness concerns (if any) of manufacturers will reduce the carbon emission reduction rate and the profit of the supply chain. If retailers have fairness concerns and consumers have low low-carbon preferences, then the total profit of the supply chain will increase, while the carbon emission reduction rate and the retail price of products will decrease.

In the aforementioned research, emphasis is given on the optimal decision and coordination problems of the lowcarbon supply chain if the members of the supply chain have some behavioral preferences, but some deficiencies remain. For instance, the behavioral factors considered are always assumed to be public, but they are usually private in practice.

\subsection{Cost Sharing of Carbon Emission Reduction among Supply} Chain Enterprises. When core enterprises in the supply chain invest in product emission reduction independently, they bear great cost pressure, while other enterprises in the supply chain do not share the corresponding cost. Such "free-riding" behavior is bound to reduce the enthusiasm of carbon emission reduction enterprises. Many scholars have conducted studies from the perspective of carbon emission reduction cost sharing among supply chain members. Zhao et al. [18] studied the supply chain system composed of one manufacturer and two retailers by constructing three difference game models and found that cost sharing can improve the profits of both manufacturers and retailers under certain conditions. Ghosh and Shah [1] discussed the impact of cost sharing on the key decisions of supply chain members. Through a comparative analysis on whether retailers share in the investment cost of emission reduction of suppliers, they found that cost sharing can improve the level of product greening and the income of supply chain members. Wang et al. [19] studied carbon emission reduction in the case of retailers' dominant position and balance of power, considering the low-carbon preference of the market, and found that cost sharing can achieve the emission reduction goal of both retailers and suppliers and improve the profit of the supply chain. Huang et al. [20] studied the cooperative emission reduction between manufacturers and retailers on the basis of the manufacturer-led dual-channel supply chain by combining low-carbon emission reduction with product promotion and found that 
retailers' sharing in carbon emission reduction costs can motivate manufacturers to reduce emission levels. Li and Wang [21] studied the low-carbon closed-loop supply chain system with carbon emission constraints and recycling by manufacturers and found that when the cooperative emission reduction adopts emission reduction cost sharing, the emission reduction and recycling levels and the retailer profit can be maximized.

All the above studies are based on the rational man hypothesis and did not consider that the social attributes of decision makers will affect the decisions of the supply chain members. In fact, when making decisions, members of the supply chain not only care about maximizing their own benefits but also pay great attention to whether the benefits are fair.

\subsection{Influence of Subjects' Fairness Preferences on Supply Chain} Decisions. Fairness preference has been introduced in some research on optimal supply chain decisions. Fehr and Schmidt [22] explored the influence of the fairness problem in the supply chain on competition and cooperation. Later, the fairness concern behaviors of supply chain members were investigated by scholars from different aspects. Under certain demand conditions, Haitao Cui et al. [23] discovered that, in case of retailers' fairness concern behaviors, manufacturers can coordinate the supply chain by setting appropriate prices. Loch and $\mathrm{Wu}$ [24] found that the supply chain can still be coordinated even if retailers resent the unfairness. The supply chain pricing and system coordination has been mainly involved in the present studies regarding the fairness problem. Caliskan-Demirag et al. [25] found that when retailers have fairness concern behaviors, the exponential demand function requires less strict conditions than the linear demand function to realize coordination. Du et al. [26] explored how the dual-party fairness concern behaviors in the supply chain influence their optimal strategies and found that when suppliers show weak concerns over fairness preferences, retailers will obtain larger shares. Zhou et al. [27] studied the influence of retailers' fairness concern on the optimal coordination of the supply chain. However, the influence of carbon quota has never been considered. Liu et al. [2] found that carbon tax supervision drives manufacturers to enhance their product sustainability by inspecting the influences of the fairness concerns of manufacturers and retailers on their own production. Zhang et al. [28] discussed the optimal supply chain decision plan under four decision-making backgrounds but only considered the fairness problem of retailers. By considering the fairness concern behaviors of members, Li et al. [29] studied the dynamic price game in a low-carbon closed-loop supply chain system. When exploring the influences of retailers' fairness concern behaviors on the pricing strategy of a double-channel supply chain, Dai et al. [30] found that the profit of manufacturers decreases while the profitability of retailers is greatly enhanced. Cao and Hou [31] studied the influence of retailers' fairness concerns belonging to their private information on the optimal supply chain decision and discovered that, under asymmetric fairness concerns, retailers' optimal order quantity and utility present a progressive declining trend with the increase in fairness concern degree. The manufacturer expected profits will progressively decline with the increase in retailers' fairness concern degree or reservation utility. By comparatively analyzing the optimal low-carbon supply chain decisions under the different fairness preferences of retailers, $\mathrm{Wu}$ et al. [32] discovered from the asymmetric fairness concern information of retailers that the retailers' bargaining power, the marginal profits of products, and the carbon emission reduction of manufacturers in the low-carbon supply chain depend on the estimated value of the retailers' fairness concern coefficient.

Different aspects of the fairness concern behaviors of supply chain members are discussed in the aforementioned literature reports, while the cooperative emission reduction and revenue sharing between the members of the lowcarbon supply chain have not been considered. Hence, the conclusions are unavoidably prone to some limitations.

In summary, cooperative emission reduction, revenue sharing, and asymmetric fairness preference have been rarely combined to study the optimal decisions of the lowcarbon supply chain. From this perspective, manufacturer-retailer game models were established under three scenarios-no fairness preference and symmetric and asymmetric fairness preferences-considering the cooperative emission reduction and revenue sharing between members of the low-carbon supply chain. Next, the optimal decisions in the low-carbon supply chain were comparatively analyzed, which is of practical significance in exploring the cooperative carbon emission reduction between manufacturers and retailers under double channels.

\section{Model Description and Symbol Explanation}

In this study, an e-commerce low-carbon supply chain was constructed with one manufacturer and one online retailer of low-carbon products. The low-carbon product manufacturer started upgrading its low-carbon product production equipment to conform to the low-carbon economic development trend, initially devoting itself to low-carbon product manufacturing and gradually moving toward lowcarbon economy. Meanwhile, the online retailer also joined the low-carbon product manufacturing to seize the lowcarbon product market and cooperated with the manufacturer and shared in the emission reduction cost.

To facilitate the subsequent research and analysis, the following hypotheses are proposed:

Assumption 1: in the two-level e-commerce low-carbon supply chain, the manufacturer plays a dominant role, while the online retailer plays a subordinate role. The decision-making order of supply chain members is as follows. First, the manufacturer decides on the carbon emission reduction and wholesale price of a unit product in the pursuit of maximizing its own profit. After observing the manufacturer's decision, the retailer formulates the retail price of low-carbon products, aiming to maximize its own utility. 
Assumption 2: according to [33], the investment cost of the low-carbon manufacturer in equipment upgrade is $c_{\theta}=1 / 2 u \theta^{2}$, where $u$ is the carbon emission reduction investment cost coefficient of the low-carbon manufacturer, and $\theta$ is the carbon emission reduction of the unit product.

Assumption 3: according to $[34,35]$, the demand for low-carbon products is assumed to have linear relations with the retail price and carbon emission reduction of products, and consumers are inclined toward the products with high carbon emission reduction and low retail price. Hence, the demand for low-carbon products is expressed as $D=a-\alpha p+\beta \theta$, where $a$ is the potential market demand for low-carbon products, $\alpha$ is the price influence coefficient, and $\beta$ represents the sensitivity coefficient of consumers to low-carbon products. According to [36], $\alpha=1$ to facilitate the concentration analysis of the carbon emission reduction of the unit product. Hence, the demand function is simplified into $D=a-p+\beta \theta$.

Assumption 4: the online retailer invests in the emission reduction of the manufacturer, where its investment proportion is $g$, and the investment proportion of the low-carbon manufacturer is $(1-g)$. Meanwhile, the he/she shares certain revenues with the manufacturer, and the revenue sharing ratio is $i$.

Assumption 5: according to Katok et al. [37], if the fairness preference of the retailer is private information, the low-carbon product manufacturer can only estimate the retailer's fairness preference coefficient and make decisions according to the estimated result.

The decision variables and main parameters are listed in Table 1 .

\section{Decision Model Construction and Solving of the Low-Carbon E-Commerce Supply Chain under Different Circumstances}

4.1. Considering the No Fairness Preference Behaviors of the Online Retailer. According to the cooperative emission reduction between the manufacturer and the online retailer, when the latter shows no fairness preference, both parties hope to acquire maximum profits as soon as possible. The decision-making process is described as follows. First, the dominant manufacturer determines the wholesale price and makes a carbon emission reduction decision. Next, the online retailer makes a retail price decision according to the optimal strategy of the manufacturer. This Stackelberg game problem is solved through the backward induction method, which is also used in the follow-up scenarios.

Theorem 1. The optimal wholesale price, the product's green degree, and the retail price are expressed as follows (see the specific deduction process in Appendix A):

$$
\begin{aligned}
\theta^{\mathrm{I}} & =\frac{\beta(a-c)}{4 u-\beta^{2}}, \\
w^{\mathrm{I}} & =\frac{c \beta^{2}(1-i)-2 u(1-g)[a+c(1-2 i)]}{(1-i)\left[\beta^{2}-4 u(1-g)\right]}, \\
p^{\mathrm{I}} & =\frac{c \beta^{2}-u(1-g)(3 a+c)}{\beta^{2}-4 u+4 g u} .
\end{aligned}
$$

The optimal profits of the low-carbon product manufacturer and the online retailer are calculated as follows:

$$
\begin{aligned}
\pi_{m}^{\mathrm{I}} & =\frac{u(a-c)^{2}(1-g)}{2\left(4 u-\beta^{2}-4 g u\right)}, \\
\pi_{r}^{\mathrm{I}} & =\frac{u(a-c)^{2}\left(2 u g^{2}-\beta^{2} g-4 u g+2 u\right)}{2\left(4 u-\beta^{2}-4 g u\right)^{2}} .
\end{aligned}
$$

4.2. Considering the Symmetric Fairness Preference Behaviors of the Online Retailer. Under this circumstance, the online retailer shows symmetric fairness preference behaviors, and even if this fairness preference information is public, the retailer pays equal attention to its own profit and the fair profit allocation. At this moment, the optimal decision of the manufacturer is to maximize its profits, while the retailer is expected to maximize the utility of its fairness preference.

Theorem 2. The optimal wholesale price, the product's green degree, and the retail process are presented below (see the specific deduction process in Appendix A):

$$
\begin{aligned}
w^{\Pi} & =\frac{(1+\lambda)\left[2 u a(1-g)-c \beta^{2}(1-i)-4 u i c(1-g)+2 u c(1-g)\right]+4 u \lambda c(1-g)(1-i)}{(1+\lambda)\left[4 u(1-g)-\beta^{2}(1-i)-4 u i(1-g)\right]+4 u \lambda(1-i)(1-g)}, \\
\theta^{\Pi} & =\frac{\beta(1+\lambda)(a-) c}{(1+\lambda)\left[4 u(1-g)-\beta^{2}\right]+4 u \lambda(1-g)}, \\
p^{\Pi} & =\frac{u(1+2 \lambda)(3 a-c g-3 a g+c)-\beta^{2} c(1+\lambda)}{4 u(1+2 \lambda)(1-g)-\beta^{2}(1+\lambda)}
\end{aligned}
$$


TABLe 1: Definitions of main parameters.

\begin{tabular}{lc}
\hline Parameter & Meaning \\
\hline$w$ & Product wholesale price of low-carbon product manufacturer \\
$p$ & Product sales price of online retailer \\
$c$ & Production cost of unit product \\
$m$ & Low-carbon product manufacturer \\
$r$ & Online retailer \\
$\lambda$ & Real fairness preference coefficient of online retailer \\
$\eta$ & Online retailer's real fairness preference coefficient estimated by the manufacturer \\
I & No fairness preference of online retailer \\
II & Symmetric fairness preference of online retailer \\
III & Asymmetric fairness preference of online retailer \\
\hline
\end{tabular}

The optimal utility of the low-carbon product manufacturer and that of the online retailer are as follows:

$$
\begin{aligned}
U_{m}^{\Pi}= & \pi_{m}^{\Pi}=\frac{u(a-c)^{2}(1-g)(1+\lambda)}{2\left[4 u(1+2 \lambda)(1-g)-\beta^{2}(1+\lambda)\right]}, \\
U_{r}^{\Pi}= & \frac{u(a-c)^{2}(1+\lambda)\left[\lambda(1+\lambda)\left(\beta^{2}+8 u\right)+2 u+g \lambda^{2}\left(8 u g-2 \beta^{2}\right)-\beta^{2} g(3 \lambda+1)\right]}{2\left[4 u(1+2 \lambda)(1-g)-\beta^{2}(1+\lambda)\right]^{2}} \\
& +\frac{u(a-c)^{2}(1+\lambda)[2 u g(1+4 \lambda)(g-2)]}{2\left[4 u(1+2 \lambda)(1-g)-\beta^{2}(1+\lambda)\right]^{2}} .
\end{aligned}
$$

4.3. Considering the Asymmetric Fairness Preference Behaviors of the Online Retailer. Under this circumstance, the online retailer shows asymmetric fairness preference behaviors; that is, it was unwilling to disclose its real fairness preference coefficient. Therefore, the manufacturer could only estimate the real fairness preference coefficient of the retailer. Next, the manufacturer makes its decisions according to the estimated coefficient. The optimal decision of the manufacturer is to maximize its profits, while the retailer is expected to maximize the utility of its fairness preference.

Theorem 3. The optimal wholesale price, the product green degree, and the retail price are described as follows (see the specific deduction process in Appendix A):

$$
\begin{aligned}
w^{\mathrm{III}}= & \frac{(1+\eta)\left[2 u a(1-g)-c \beta^{2}(1-i)-4 u i c(1-g)+2 u c(1-g)\right]+4 u \eta c(1-g)(1-i)}{(1+\eta)\left[4 u(1-g)-\beta^{2}(1-i)-4 u i(1-g)\right]+4 u \eta(1-i)(1-g)}, \\
\theta^{\mathrm{III}}= & \frac{\beta(1+\eta)(a-c)}{(1+\eta)\left[4 u(1-g)-\beta^{2}\right]+4 u \eta(1-g)}, \\
p^{\mathrm{III}}= & \frac{a u(3+5 \eta-3 g+4 \lambda)-\beta^{2} c(1+\lambda)(1+\eta)+c u(1+3 \eta-g)}{(1+\lambda)\left[4 u(1+2 \eta)(1-g)-\beta^{2} c(1+\lambda)\right]} \\
& +\frac{6 a \eta \lambda u(1-g)-c \eta g u(3+2 \lambda)-a g u(5 \eta+4 \lambda)}{(1+\lambda)\left[4 u(1+2 \eta)(1-g)-\beta^{2} c(1+\lambda)\right]} .
\end{aligned}
$$

The optimal utility of the low-carbon product manufacturer and that of the online retailer are calculated as follows: 


$$
\begin{aligned}
U_{m}^{\mathrm{III}}= & \pi_{m}^{\mathrm{III}}=\frac{u(a-c)^{2}(1+\eta)(g-1)\left[\beta^{2}(1+\lambda)(1+\eta)+4 u(1+3 \eta)(g-1)+8 \eta \lambda u(g-1)\right]}{2(1+\lambda)\left[\beta^{2}(1+\eta)-4 u(1+2 \eta)(1-g)\right]}, \\
U_{r}^{\mathrm{III}}= & \frac{u(a-c)\left[\beta^{2} \eta \lambda(1+\lambda)(\eta+2)-\beta^{2} \eta g\left(2 \lambda^{2}+3 \lambda+1\right)(\eta+2)+2 u\left(g^{2}-2 g+1\right)-36 u \eta^{2} g\right]}{2(1+\lambda)\left[\beta^{2}(1+\lambda)-4 u(1+2 \eta)(1-g)\right]^{2}} \\
& +\frac{u(a-c)\left[-\beta^{2} g\left(2 \lambda^{2}+3 \lambda+1\right)+\beta^{2}(1+\lambda)+2 u \eta^{2}\left(4 \lambda^{2}+12 \lambda+9\right)\left(g^{2}+1\right)-16 u \eta^{2} g \lambda(\lambda+3)\right]}{2(1+\lambda)\left[\beta^{2}(1+\eta)-4 u(1+2 \eta)(1-g)\right]^{2}} \\
& +\frac{u(a-c)\left[4 u \eta(2 \lambda+3)\left(g^{2}-2 g+1\right)\right]}{2(1+\lambda)\left[\beta^{2}(1+\eta)-4 u(1+2 \eta)(1-g)\right]^{2}} .
\end{aligned}
$$

\section{Numerical Analysis}

The above models are numerically analyzed in this section. Some numerical examples are listed to, respectively, discuss the changes in the manufacturer's profit, the online retailer's utility, the total utility of the supply chain, the product's wholesale price, the manufacturer's carbon emission reduction, and the product's retail price with the online retailer's fairness preference coefficient $\lambda$ and investment proportion $g$ and the manufacturer's revenue sharing ratio $i$.

(1) The manufacturer's profit, the online retailer's utility, the total utility of the supply chain, the product's wholesale price, the manufacturer's carbon emission reduction, and the product retail price change with the online retailer's fairness preference coefficient $\lambda$. $a=100, c=5, u=10, g=0.3, \beta=5, \eta=0.3$, and $i=0.3$ are set. The changes in the manufacturer's profit, the total utility of the supply chain, the online retailer's utility, the product's wholesale price, the manufacturer's carbon emission reduction, and the product's retail price with the online retailer's fairness preference coefficient $\lambda$ are as shown in Figures 1-6.

The change curves of the manufacturer's profit with the online retailer's fairness preference coefficient $\lambda$ are displayed in Figure 1. The figure shows that when the online retailer shows no fairness preference, the manufacturer's profit is higher than that under the symmetric and asymmetric fairness preferences of the online retailer, reaching the maximum value. This indicates that the manufacturer's profit is reduced by a large margin due to the online retailer's fairness preference behaviors. In the case of the change in $\lambda$, the manufacturer's profit changes in the reverse direction, so the retailer's fairness preference imposes a negative impact on the manufacturer's profit.

The change curves of the retailer's utility with its fairness preference coefficient $\lambda$ are as shown in Figure 2. The figure shows that, under the asymmetric fairness preferences of the online retailer, the online retailer's utility changes with $\lambda$; that is, it is enhanced with $\lambda$, indicating that, under the asymmetric fairness preferences of the online retailer, the online retailer's utility changes in the same direction as $\lambda$, and the online retailer's fairness preference has a positive influence on itself.

The change curves of the total utility of the supply chain with the change in the online retailer's fairness preference coefficient $\lambda$ are displayed in Figure 3. The figure shows that, under the symmetric and asymmetric fairness preferences of the online retailer, the overall utility of the supply chain is lower than that when the online retailer has no fairness preference, indicating that the online retailer's fairness preferences have adverse impacts, so the overall utility of supply chain declines. Under the asymmetric fairness preferences of the online retailer, the overall utility of the supply chain declines with the enhancement of $\lambda$, indicating that when the online retailer shows symmetric fairness preferences, the total utility of the supply chain weakens.

The change curves of the product retail price owing to the change in the online retailer's fairness preference coefficient $\lambda$ are displayed in Figure 4. The figure shows that, under the symmetric fairness preference of the online retailer, the product retail price is lowered with the continuous increase in $\lambda$. When the online retailer shows asymmetric fairness preferences, the product retail price continuously increases with $\lambda$, indicating that, under the asymmetric fairness preferences of the online retailer, the product retail price formulated by the online retailer is positively correlated with its own fairness preference coefficient $\lambda$. This finding also reveals that the bargaining power of the online retailer has a positive correlation with fairness preference coefficient $\lambda$.

The change curves of the manufacturer's carbon emission reduction with the online retailer's fairness preference coefficient $\lambda$ are as shown in Figure 5. The figure shows that, under the symmetric fairness preferences of the online retailer, the manufacturer decelerates its carbon emission reduction as $\lambda$ continuously increases, indicating that when the online retailer has symmetric fairness preferences, the high attention given by the online retailer to fairness would weaken the manufacturer's enthusiasm for manufacturing green products. Under the asymmetric fairness preferences of the online retailer, the manufacturer's carbon emission reduction is maintained with the increase in $\lambda$, indicating that, under the asymmetric fairness preference of the online retailer, the manufacturer's carbon emission reduction is 


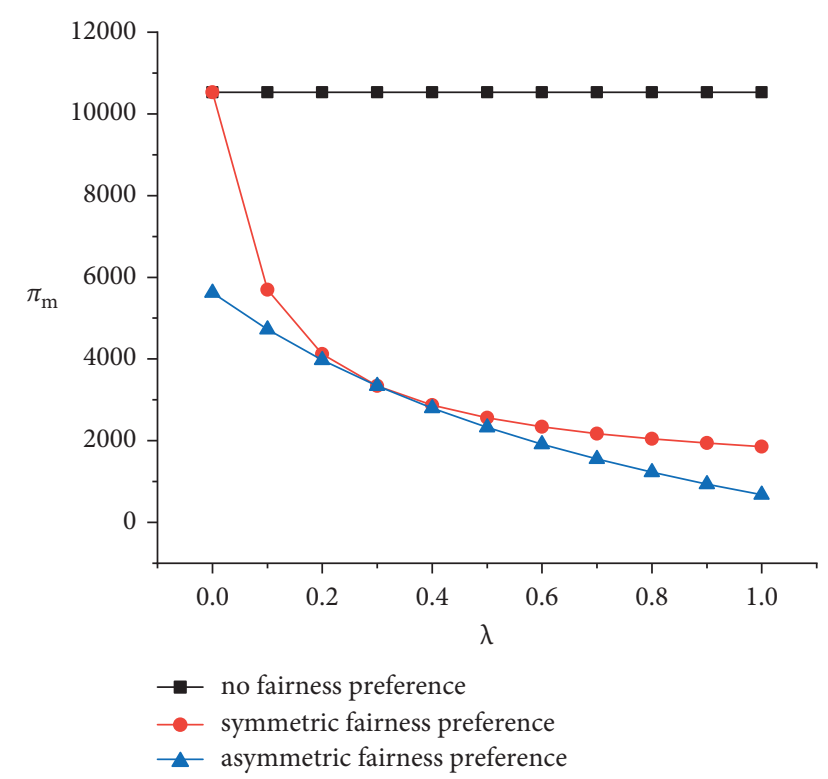

Figure 1: Change curves of manufacturer's profit with online retailer's fairness preference coefficient $\lambda$.

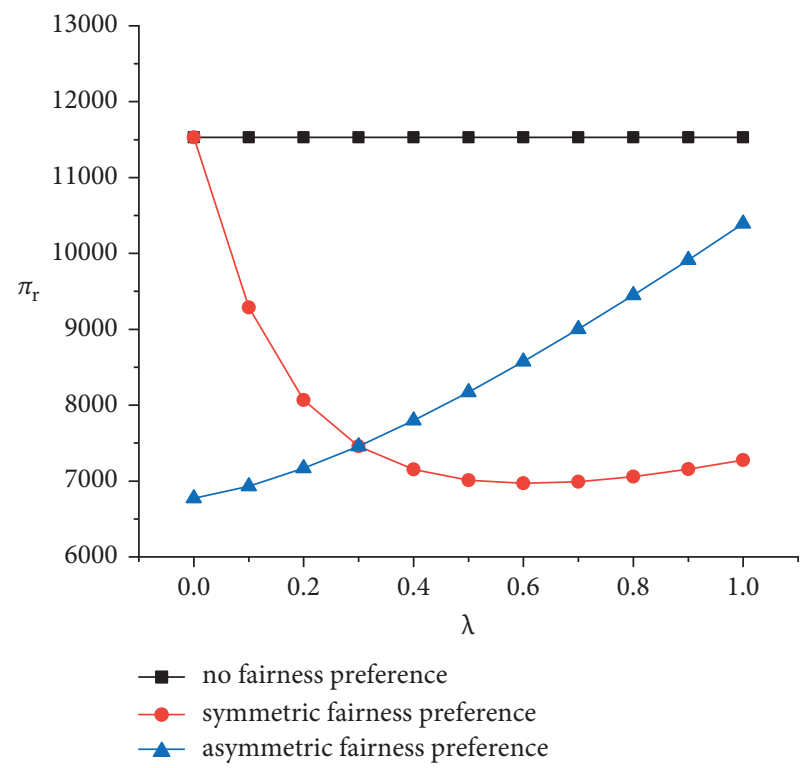

FIgURE 2: Change curves of retailer's utility with its fairness preference coefficient $\lambda$.

unrelated to the online retailer's fairness preference coefficient $\lambda$.

The change curves of the product wholesale price with the online retailer's fairness preference coefficient $\lambda$ are displayed in Figure 6. Under the symmetric fairness preferences of the online retailer, the manufacturer would lower the price of the products sold to the online retailer, that is, lowering the wholesale price with the increase in $\lambda$, indicating that, under the asymmetric fairness preferences of the online retailer, the product wholesale price is negatively correlated with the online retailer's fairness preference coefficient. When the online retailer has asymmetric fairness

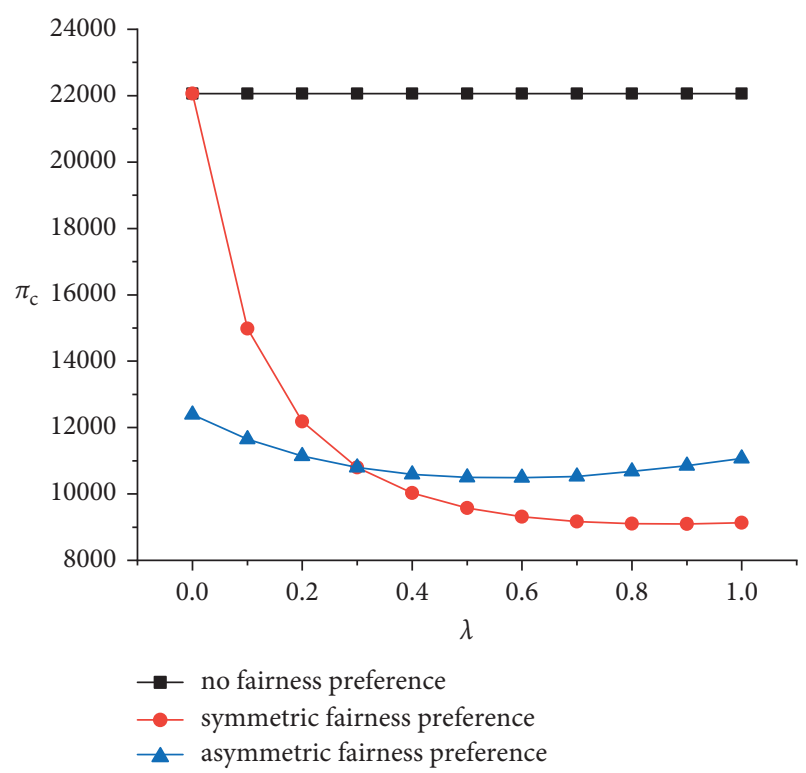

Figure 3: Change curves of total utility of the supply chain with online retailer's fairness preference coefficient $\lambda$.

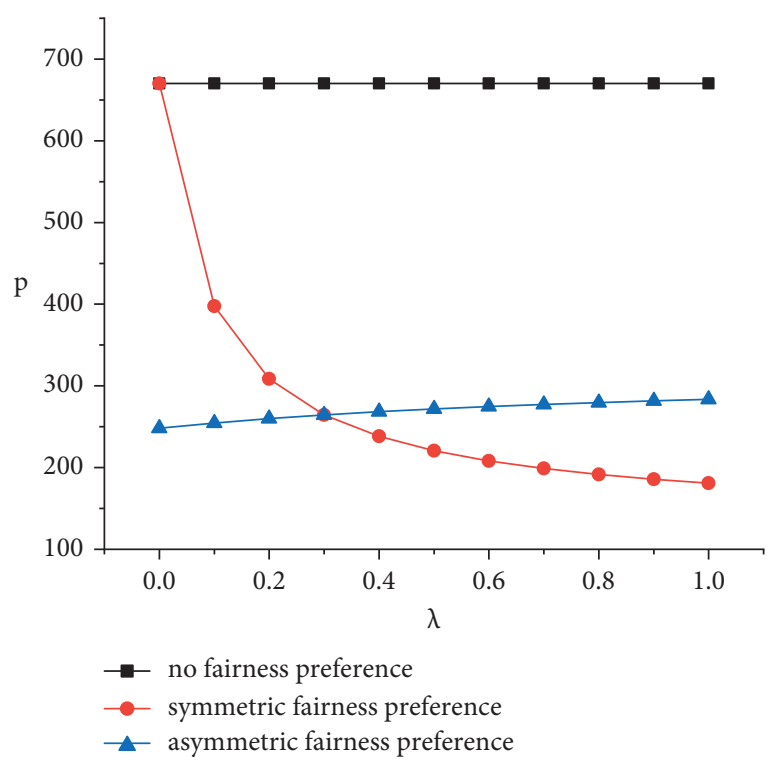

Figure 4: Change curves of product retail price with online retailer's fairness preference coefficient $\lambda$.

preferences, regardless of how its fairness preference coefficient is adjusted, the manufacturer's product wholesale price would remain unchanged, meaning that, under the asymmetric fairness preferences of the online retailer, the product wholesale price is unrelated to the retailer's fairness preference coefficient.

In the case of the asymmetric equity preference of online retailers, manufacturers can only make decisions on the wholesale price and the carbon emission reduction on the basis of the estimated equity concern coefficient of retailers. Once the estimated equity concern coefficient is determined, the wholesale price and the carbon emission reduction will 


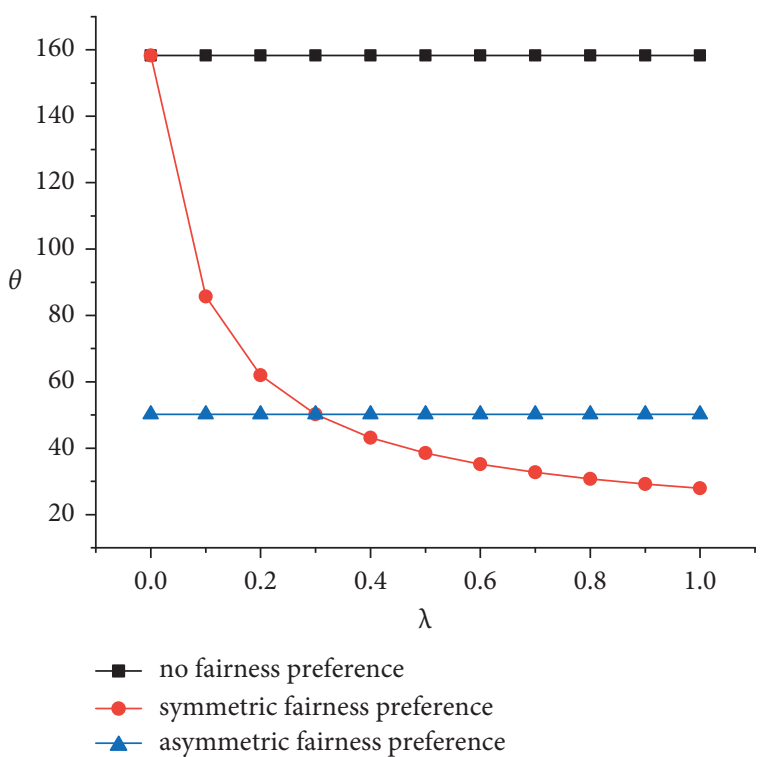

Figure 5: Change curves of manufacturer's carbon emission reduction with online retailer's fairness preference coefficient $\lambda$.

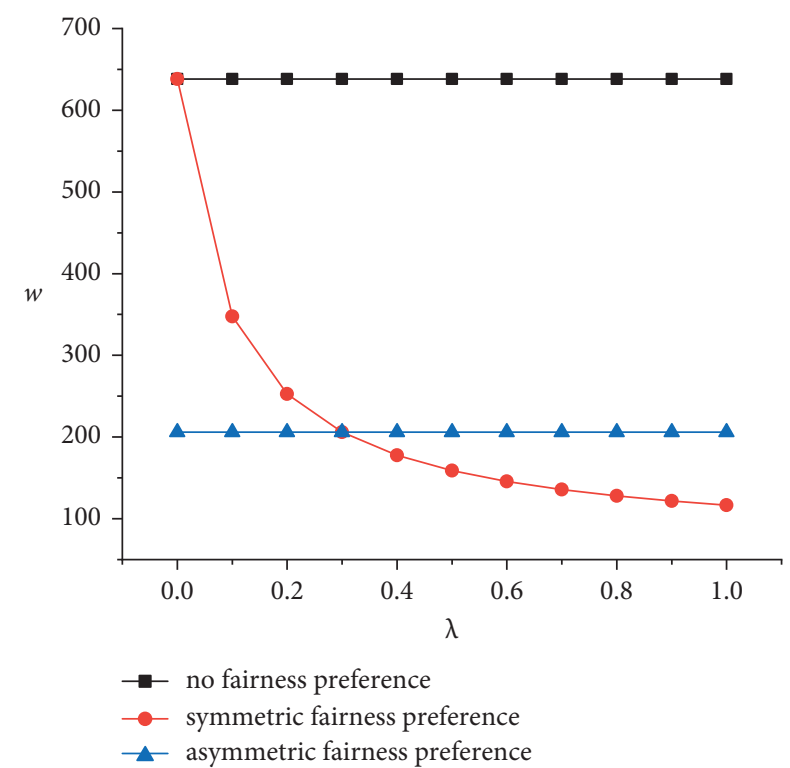

FIGURE 6: Change curves of product wholesale price with online retailer's fairness preference coefficient $\lambda$.

remain unchanged. If the true fairness coefficient of concern is underestimated, the wholesale prices and the carbon emissions will be higher than when decisions are made based on the real fairness concerns coefficient; when the retailers' real fairness concerns coefficient is high, the retailers' decisions determine the sales price as high as possible, while increasing its profits, but also can reduce the market demand, manufacturers lower profits. If the true equity concern coefficient is overestimated, then the wholesale price and the carbon emission reduction will be lower than when the decision is made based on the true equity concern coefficient. A low wholesale price will reduce the profit of the unit product, and a small carbon emission reduction will reduce the market demand, decreasing the profit of both retailers and manufacturers. Therefore, asymmetric equity preference behavior factors reduce the manufacturers' profits. Furthermore, the online retailers' selling price and utility, the manufacturers' wholesale price, and the carbon emission reduction are all negatively correlated with their asymmetric equity preference coefficients.

(2) The manufacturer's profit, the online retailer's utility, the total utility of the supply chain, the product's wholesale price, the product's retail price, and the manufacturer's carbon emission reduction vary with the retailer's investment proportion g. $a=100$, $c=5, u=10, \lambda=0.4, \beta=5, \eta=0.3$, and $i=0.3$ are set. The changes in the manufacturer's profit, the online retailer's utility, the total utility of the supply chain, the product's wholesale price, the product's retail price, and the manufacturer's carbon emission reduction with the online retailer's investment proportion $g$ are presented from Figures 7 to 12 .

The change curves of the manufacturer's profit with the retailer's investment proportion $g$ are displayed in Figure 7 . Within the feasible region of the online retailer's investment proportion $g$, the manufacturer's profit increases with $g$ under no fairness preference and the symmetric and asymmetric fairness preferences of the online retailer, indicating that, under the three circumstances, the manufacturer's profit is positively correlated with the retailer's investment proportion $g$. Under the asymmetric fairness preferences of the online retailer, the growth amplitude of the manufacturer's profit is smaller than that under the symmetric fairness preferences, hinting that the asymmetric fairness preference of the online retailer restricts the growth of the manufacturer's profit and thus has a negative impact on the manufacturer.

The change curves of the retailer's utility with its investment proportion $g$ are as shown in Figure 8. The figure shows that, within the feasible region of the online retailer's investment proportion $g$, the retailer's utility is elevated with $g$ under no fairness preference and its symmetric and asymmetric fairness preferences. This indicates that, under the three circumstances, the online retailer's utility presents a positive correlation with its investment proportion $g$. Under the asymmetric fairness preferences of the online retailer, when the online retailer only invests a small part, its utility does not decline, but instead grows, indicating that the manufacturer's carbon emission reduction and its enthusiasm for production are driven by the online retailer's investment.

The change curves of the total utility of the supply chain with the retailer's investment proportion $g$ are as shown in Figure 9. The figure shows that, within the feasible region of the online retailer's investment proportion $g$, the total utility of the e-commerce low-carbon supply chain increases with $g$ under three circumstances: no fairness preference and the symmetric and asymmetric fairness preferences of the online retailer. This finding reflects that, under the three circumstances, the total utility of the e-commerce low-carbon supply chain is positively correlated with the retailer's 


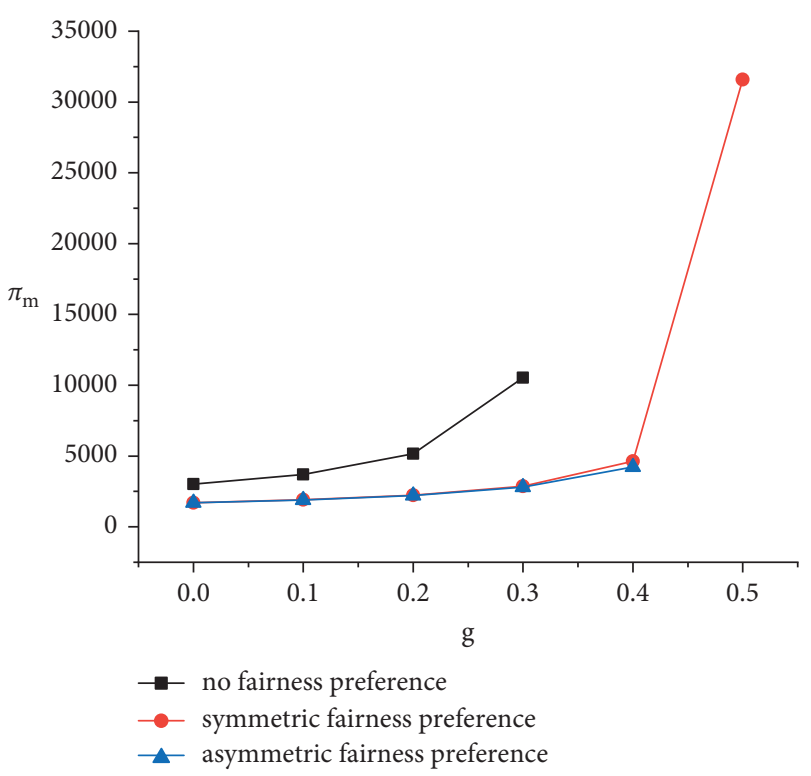

Figure 7: Change curves of manufacturer's profit with online retailer's investment proportion $g$.

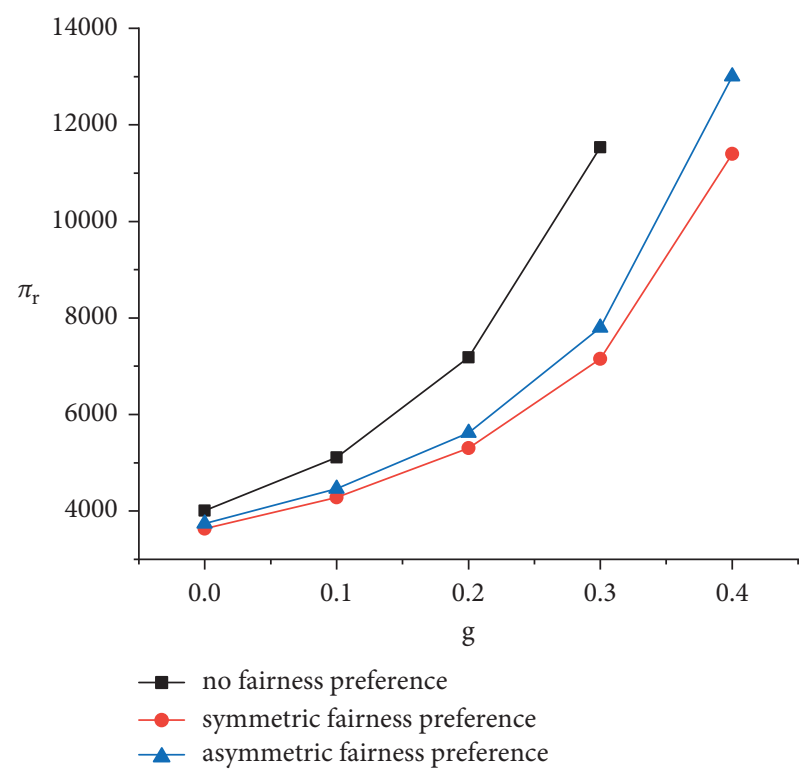

Figure 8: Change curves of online retailer's utility with its investment proportion $g$.

investment proportion. When the online retailer shows asymmetric fairness preferences, the utility of the e-commerce low-carbon supply chain is lower than that under the asymmetric fairness preferences of the online retailer, implying that the asymmetric fairness preferences of the online retailer more effectively facilitate the utility growth of the supply chain than the asymmetric fairness preferences.

The change curves of the manufacturer's carbon emission reduction with the retailer's investment proportion $g$ are displayed in Figure 10. The figure shows that, within the feasible region of the online retailer's investment proportion $g$, the manufacturer's carbon emission reduction increases

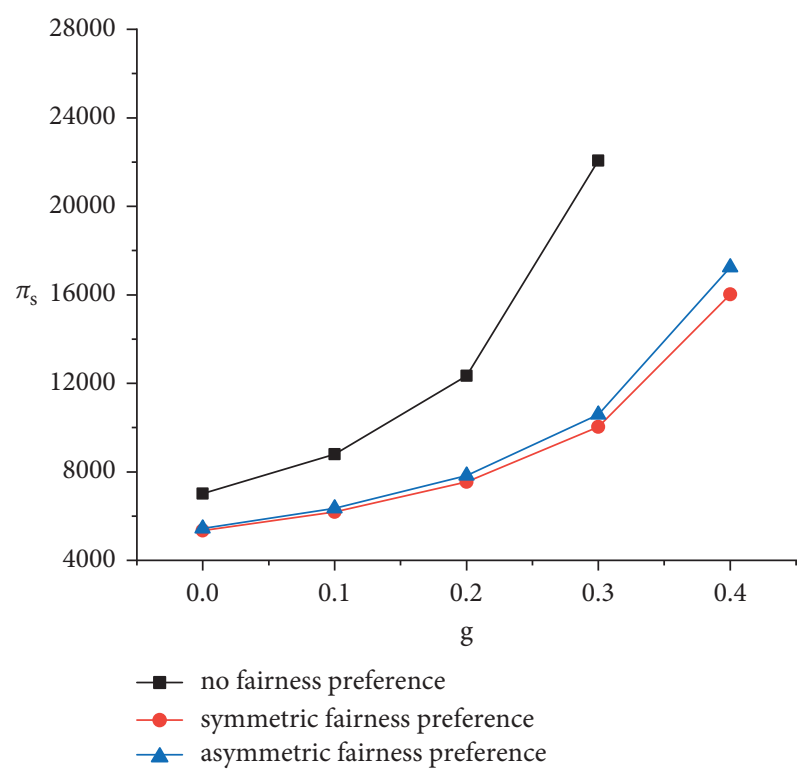

Figure 9: Change curves of total utility of the supply chain with online retailer's investment proportion $g$.

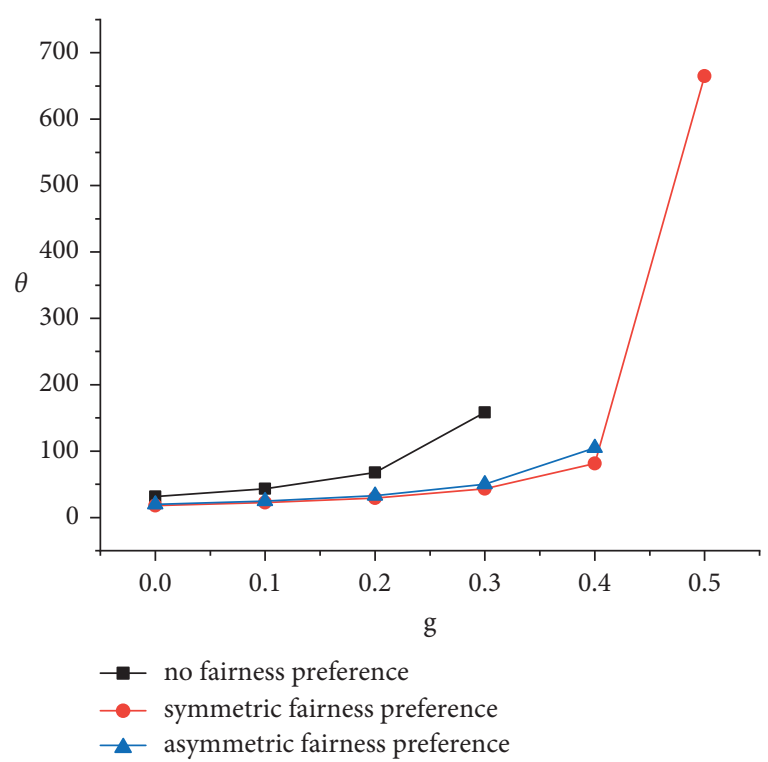

FIGURE 10: Change curves of manufacturer's carbon emission reduction with online retailer's investment proportion $g$.

with $g$ under three circumstances: no fairness preference and the symmetric and asymmetric fairness preferences of the online retailer, indicating that, under the three circumstances, the manufacturer's carbon emission reduction presents a positive correlation with the online retailer's investment proportion. Under the asymmetric fairness preferences of the online retailer, the growth amplitude of the manufacturer's carbon emission reduction is greater than that under the asymmetric fairness preferences, indicating that the asymmetric fairness preferences of the online retailer restrict the manufacturer's carbon emission reduction and weaken its enthusiasm for carbon emission reduction. 


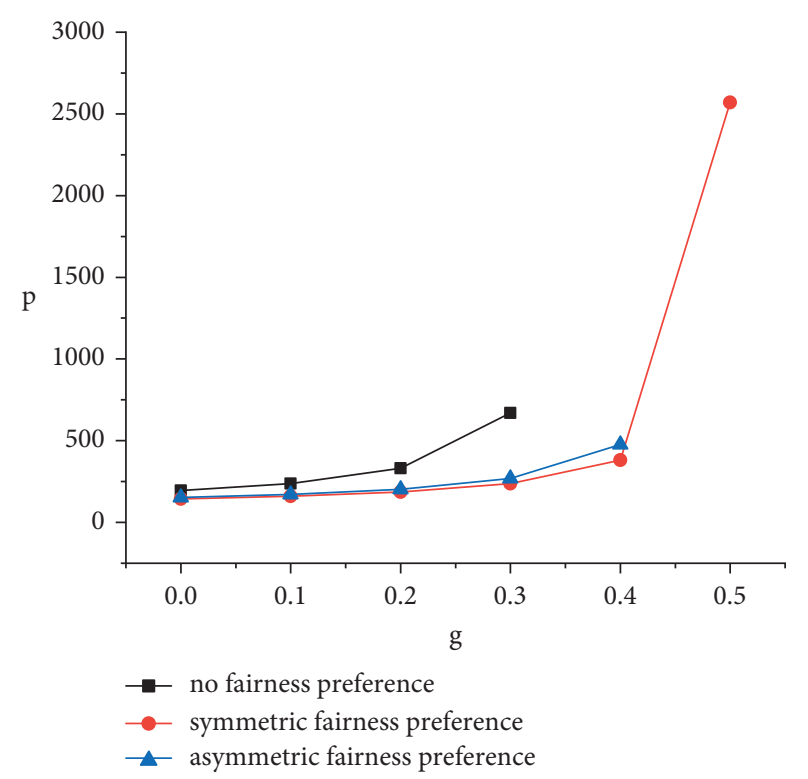

FIGURE 11: Change curves of product retail price with online retailer's investment proportion $g$.

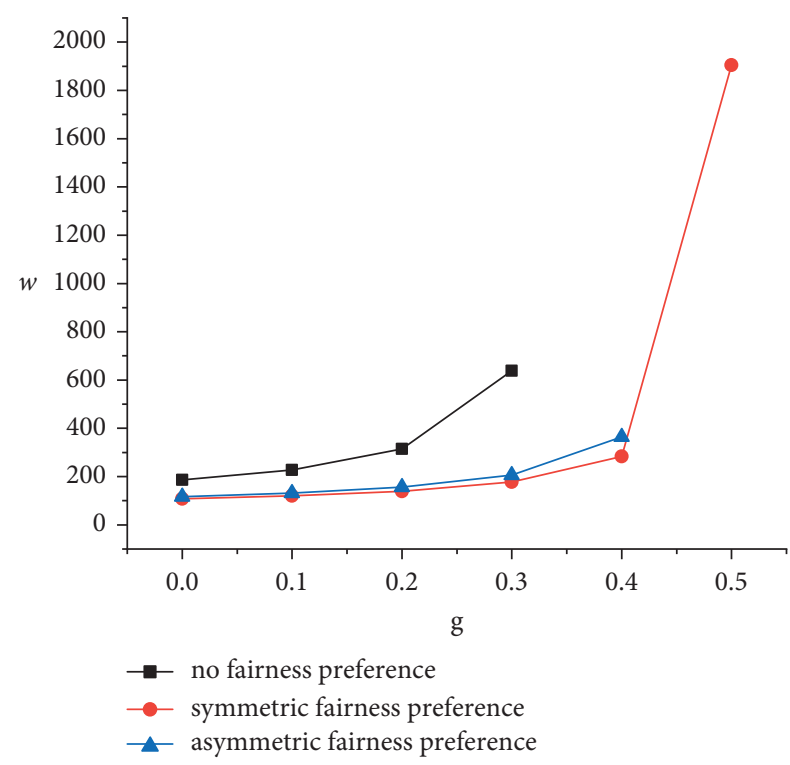

FIGURE 12: Change curves of product wholesale price with online retailer's investment proportion $g$.

The change curves of the product retail price with the online retailer's investment proportion $g$ are as shown in Figure 11. The figure shows that, under the aforementioned three circumstances and within the feasible region of the online retailer's investment proportion $g$, the product retail price increases with $g$. This finding shows that, under the three circumstances, a positive correlation exists between the product retail price and the online retailer's investment proportion $g$. Under the symmetric fairness preferences of the online retailer, the growth amplitude of the product retail price is greater than that under the asymmetric fairness preferences, indicating that the bargaining power of the online retailer is weakened by the asymmetric fairness preferences.
The change curves of the product wholesale price with the retailer's investment proportion $g$ are presented in Figure 12. The figure shows that, within the feasible region of the online retailer's investment proportion $g$, the product wholesale price increases with $g$ under all of the three circumstances. Under the three circumstances, the product wholesale price is positively correlated with the online retailer's investment proportion $g$. Under the asymmetric fairness preferences of the online retailer, the growth amplitude of the product wholesale price is smaller than that under the symmetric fairness preferences, indicating that the asymmetric fairness preferences weaken the growth capability of the manufacturer's wholesale price, and the marginal profit of low-carbon products is also cut down.

If online retailers invest in emission reduction, the cost of carbon emission reduction, the pressure on manufacturers, and the investment ratio can be reduced; the greater the manufacturer of carbon emission reduction, the smaller the cost pressure, when making decisions you can make the product of carbon emissions bigger, the market demand increases accordingly, and retailers, when making decisions, also can improve the product sales price accordingly. Therefore, within the feasible region, the proportion of emission reduction investment of online retailers is positively correlated with the manufacturer's profit, the online retailer's utility, the supply chain's total utility, the carbon emission reduction, the product's retail price, and the product's wholesale price.

(3) The manufacturer's profit, the online retailer's utility, the total utility of the supply chain, the product's wholesale price, the product's retail price, and the manufacturer's carbon emission reduction change with the manufacturer's revenue sharing ratio $i$.

Deduction 1: when the online retailer shows different fairness preferences and its pricing decision is optimal, its product retail price and utility and the manufacturer's carbon emission reduction and profit are unrelated to the manufacturer's revenue sharing ratio, and the singleproduct profit of the manufacturer is positively correlated with its revenue sharing ratio (see the specific deduction process in Appendix B).

$a=100, c=5, u=10, \lambda=0.4, \beta=5, \eta=0.3$, and $g=$ 0.3 are assumed. Deduction 1 indicates that only the manufacturer's product wholesale price is associated with $i$, so only the correlation between the manufacturer's revenue sharing ratio $i$ and its product wholesale price is analyzed in this hypothesis, as shown below.

The change curves of the manufacturer's profit due to the change in the manufacturer's revenue sharing ratio $i$ are displayed in Figure 13. The figure shows that the product wholesale price increases with the value of $i$ under all of the three circumstances, indicating that the manufacturer's product wholesale price is positively correlated with its revenue sharing ratio, and the manufacturer tends to guarantee its own benefits by elevating its own wholesale price. Moreover, the product's wholesale price under the asymmetric fairness preferences of the online retailer is higher than that under the symmetric fairness preferences, 


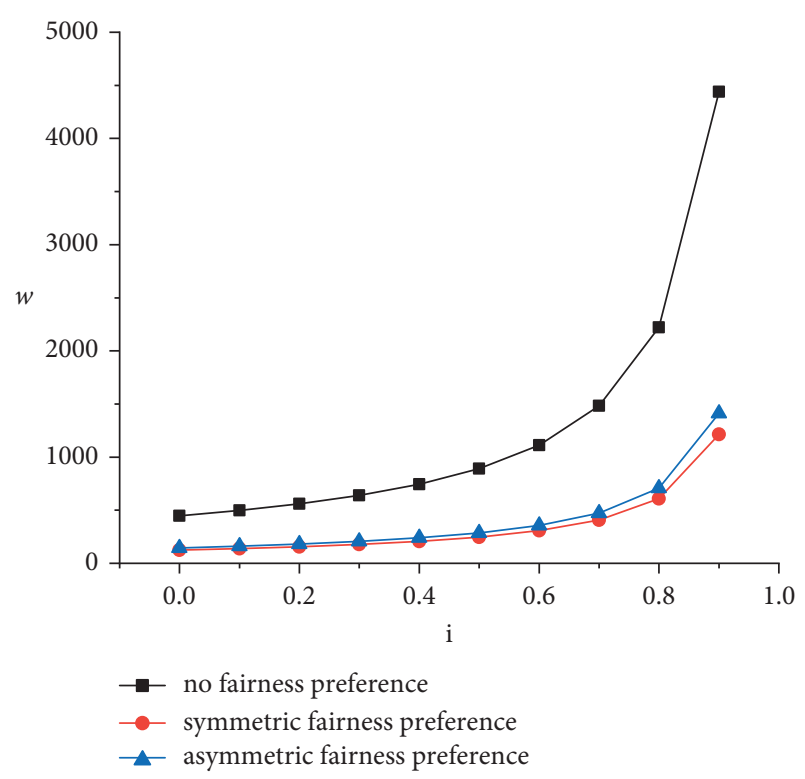

FIGURE 13: Change curves of product wholesale price with manufacturer's revenue sharing ratio $i$.

indicating that the online retailer shows a weaker bargaining power under the asymmetric fairness preferences than that under the symmetric fairness preferences.

\section{Conclusions and Expectations}

\subsection{Conclusions}

(1) The asymmetric fairness preferences of the online retailer cut down the manufacturer's profit. Specifically, the manufacturer's profit under the asymmetric fairness preferences of the online retailer is lower than that under the symmetric fairness preferences. Hence, the online retailer's asymmetric fairness preferences go against the overall cooperative development of the supply chain. The utility of the online retailer itself is continuously growing under the asymmetric fairness preferences, which, however, weakens the overall utility of the supply chain.

(2) Under the asymmetric fairness preferences of the online retailer, the manufacturer's carbon emission reduction and the product's wholesale price are negatively correlated with the estimated value of the online retailer's fairness preference coefficient. In this case, the manufacturer cannot blindly estimate the real fairness preference coefficient of the online retailer. If the coefficient is underestimated, the wholesale price of low-carbon products and the carbon emission reduction will be high, and vice versa.

(3) As the proportion of the online retailer's investment in the cooperative emission reduction is elevated, the manufacturer's profit, the total utility of the supply chain, the carbon emission reduction, the product's retail price, and the wholesale price increase, presenting positive correlations with the online retailer's investment proportion. However, such positive correlations hold true only within the feasible region of the online retailer's investment proportion.

\subsection{Management Enlightenments}

(1) In the practical manufacturer-online retailer cooperation, the manufacturer can sign an agreement with the online retailer, specifying that the online retailer shall not conceal its real fairness preference coefficient to mitigate the adverse effects brought by the asymmetric fairness preferences of the online retailer to the manufacturer.

(2) To better develop the low-carbon economy, government sectors must take some measures to keep the manufacturer informed of the online retailer's real fairness preference coefficient and prevent the overestimation of the online retailer's fairness preference coefficient and the manufacturer from cutting down its carbon emission reduction and curbing its enthusiasm for developing the low-carbon economy.

(3) When cooperating with the manufacturer, the online retailer can elevate its own investment proportion as far as possible within a certain feasible region, so as to bring higher utility to itself. Meanwhile, this is good for the overall development of the e-commerce low-carbon supply chain. The further development of the overall e-commerce low-carbon supply chain will contribute to further development of the online retailer.

6.3. Research Expectations. Under a new research background, the cooperative emission reduction between the online retailer and the manufacturer is combined to analyze the changes in the supply chain decisions in case of asymmetric fairness preferences. However, only the singlechannel low-carbon supply chain is considered, so further research remains to be done by combining the multichannel low-carbon supply chain with the fairness preference behaviors. In addition, the research subjects involved are mainly based on the two-level low-carbon supply chain. However, other subjects, like distributor, supplier, and consumer, are included in the supply chain and differ in behavioral preferences, so more decision subjects can be included in future research.

\section{Appendix}

\section{A. Theorems Proof}

A. 1. Theorem 1 Proof. According to the manufacturer-online retailer cooperative emission reduction, the decision-making objective of both manufacturer and online retailer is to seek for the maximum profit when the online retailer shows no fairness preference behaviors. The decision-making objective function is expressed as follows: 


$$
\begin{aligned}
& \max \pi_{m}=(1-i)(w-c)(a-p+\beta \theta)-\frac{1}{2} u \theta^{2}(1-g) \\
& \max \pi_{r}=(p-w)(a-p+\beta \theta)-\frac{1}{2} u \theta^{2} g+i(w-c)(a-p+\beta \theta) .
\end{aligned}
$$

According to Stackelberg game theory, the manufacturer that plays a dominant role should formulate the wholesale price and make decisions about the carbon emission reduction after knowing about the online retailer's pricing decisions. The optimal response function of the online retailer is solved through the backward induction method as follows:

$$
p=\frac{1}{2}(a+\beta \theta+w-w i+c i)
$$

Equation (A.3) is substituted into equation (A.1). According to the existence condition of the extreme value of a multivariate function, $(1 / 4)(1-i)^{2} \beta^{2}-u(1-g)(1-i)^{2}<0$ should be met if a maximum value exists in equation (A.1). In this case, the first-order partial derivatives of $w$ and $\theta$ in equation (A.1) are solved, the equation obtained on this basis is set as 0 , and then the following equation is derived:

$$
\begin{aligned}
& \frac{\partial \pi_{m}}{\partial w}=(1-i)\left(\frac{1}{2} a+\frac{1}{2} \beta \theta-c i+w i-w+\frac{1}{2} c\right)=0, \\
& \frac{\partial \pi_{m}}{\partial \theta}=\frac{1}{2}(1-i) w \beta-\frac{1}{2}(1-i) c \beta-u \theta(1-g)=0 .
\end{aligned}
$$

$w^{\mathrm{I}}$ and $\theta^{\mathrm{I}}$ can be solved by the simultaneous system of equations as follows:

$$
\begin{aligned}
\theta^{I} & =\frac{\beta(a-c)}{4 u-\beta^{2}}, \\
w^{I} & =\frac{c \beta^{2}(1-i)-2 u(1-g)[a+c(1-2 i)]}{(1-i)\left[\beta^{2}-4 u(1-g)\right]} .
\end{aligned}
$$

$w^{I}$ and $\theta^{\mathrm{I}}$ are substituted into equation (A.3) to solve the pricing decision of the online retailer as follows:

$$
p^{I}=\frac{c \beta^{2}-u(1-g)(3 a+c)}{\beta^{2}-4 u+4 g u} .
$$

Equations (A.6)-(A.8) are substituted into equations (A.1) and (A.2) to obtain the profits of the manufacturer and online retailer:

$$
\begin{aligned}
\pi_{m m}^{\mathrm{I}} & =\frac{u(a-c)^{2}(1-g)}{2\left(4 u-\beta^{2}-4 g u\right)}, \\
\pi_{r}^{\mathrm{I}} & =\frac{u(a-c)^{2}\left(2 u g^{2}-\beta^{2} g-4 u g+2 u\right)}{2\left(4 u-\beta^{2}-4 g u\right)^{2}} .
\end{aligned}
$$

\section{A. 2. Theorem 2 Proof}

In this case, the decision-making objective function of the online retailer is as follows:

$$
\max U_{r}=\pi_{r}+\lambda\left(\pi_{r}-\pi_{m}\right) .
$$

Equations (A.1) and (A.2) are substituted into equation (A.11) to obtain equation (A.12):

$$
\begin{aligned}
& \max U_{r}=(p-w)(a-p+\beta \theta)-\frac{1}{2} u g \theta^{2}+i(w-c)(a-p+\beta \theta) \\
& +\lambda\left[(p-w)(a-p+\beta \theta)-\frac{1}{2} u g \theta^{2}+i(w-c)(a-p+\beta \theta)-(1-i)(w-c)(a-p+\beta \theta)-\frac{1}{2} u \theta^{2}(1-g)\right] \\
& p^{\mathrm{II}}=\frac{(1+\lambda)(a+\beta \theta+w-i w+i c)+\lambda(1-i)(w-c)}{2(1+\lambda)} .
\end{aligned}
$$
chain, it will attempt to determine the pricing policies of its followers before making its own decisions according to Stackelberg game. The first-order condition of equation (A.12) is set as 0 to solve the optimal response function of the online retailer to the retail price as follows:
Equation (A.13) is substituted into equation (A.1). According to the existence condition of the extreme value of a multivariate function, $\left.\beta^{2}(1-i)^{2}(1+\lambda)\right)+4 u(1-i)(1-$ 
g) $(1+\lambda)(i-1)-4 u \lambda(1-g)(1-i)^{2}<0$ should be met if an extreme value exists in the manufacturer expected profit function. In this case, the first-order partial derivatives of $w^{\text {II }}$ and $\theta^{\mathrm{II}}$ in equation (A.1) are solved and equalized to 0 , so the following equation is obtained:

$$
\begin{aligned}
& \frac{\partial \pi_{m}}{\partial w}=(1-i)\left(\frac{1}{2} a+\frac{1}{2} \beta \theta-i c-w+i w+\frac{1}{2} c\right)-\frac{\lambda w(1-i)^{2}}{1+\lambda}+\frac{\lambda c(1-i)^{2}}{1+\lambda}=0, \\
& \frac{\partial \pi_{m}}{\partial \theta}=\frac{1}{2} \beta(1-i)(w-c)-u \theta k=0 .
\end{aligned}
$$

Through the simultaneous system of equations (A.14) and (A.15), $w^{\mathrm{II}}$ and $\theta^{\mathrm{II}}$ can be solved as follows:

$$
\begin{aligned}
w^{\mathrm{II}} & =\frac{(1+\lambda)\left[2 u a(1-g)-c \beta^{2}(1-i)-4 u i c(1-g)+2 u c(1-g)\right]+4 u \lambda c(1-g)(1-i)}{(1+\lambda)\left[4 u(1-g)-\beta^{2}(1-i)-4 u i(1-g)\right]+4 u \lambda(1-i)(1-g)}, \\
\theta^{\mathrm{II}} & =\frac{\beta(1+\lambda)(a-c)}{(1+\lambda)\left[4 u(1-g)-\beta^{2}\right]+4 u \lambda(1-g)} .
\end{aligned}
$$

Equations (A.16) and (A.17) are substituted into equation (A.13) to solve the pricing decision function of the online retailer as follows:

$$
p^{\mathrm{II}}=\frac{u(1+2 \lambda)(3 a-c g-3 a g+c)-\beta^{2} c(1+\lambda)}{4 u(1+2 \lambda)(1-g)-\beta^{2}(1+\lambda)} .
$$

By substituting equations (A.15)-(A.18) into equations (A.1) and (A.12), respectively, the manufacturer's utility and the online retailer's utility are solved as follows:

$$
\begin{aligned}
U_{m}^{\mathrm{II}}= & \pi_{m}^{\mathrm{II}}=\frac{u(a-c)^{2}(1-g)(1+\lambda)}{2\left[4 u(1+2 \lambda)(1-g)-\beta^{2}(1+\lambda)\right]}, \\
U_{r}^{\mathrm{II}}= & \frac{u(a-c)^{2}(1+\lambda)\left[\lambda(1+\lambda)\left(\beta^{2}+8 u\right)+2 u+g \lambda^{2}\left(8 u g-2 \beta^{2}\right)-\beta^{2} g(3 \lambda+1)\right]}{2\left[4 u(1+2 \lambda)(1-g)-\beta^{2}(1+\lambda)\right]^{2}} \\
& +\frac{u(a-c)^{2}(1+\lambda)[2 u g(1+4 \lambda)(g-2)]}{2\left[4 u(1+2 \lambda)(1-g)-\beta^{2}(1+\lambda)\right]^{2}} .
\end{aligned}
$$

A. 3. Theorem 3 Proof (Asymmetric Fairness Preferences of Online Retailer). Under this circumstance, the online retailer will show a tendency to fairness preference, and it is reluctant to disclose its real fairness preference coefficient, which can therefore only be estimated by the manufacturer. The manufacturer will make decisions based on the estimation result. In decision-making, the manufacturer still aims to maximize its own profit. The manufacturer's profit function is identical with equation (A.1), and the manufacturer will deem the online retailer's decision-making objective function as follows:

$$
\max U=\pi_{r}+\eta\left(\pi_{r}-\pi_{m}\right) \text {. }
$$

Equations (A.1) and (A.2) are substituted into equation (A.21). Through the backward induction method, the optimal price response function of the online retailer estimated by the manufacturer under asymmetric fairness preferences can be solved using equation (A.22):

$$
p^{\mathrm{III}}=\frac{u(1+2 \eta)(3 a-c g-3 a g+c)-\beta^{2} c(1+\eta)}{4 u(1+2 \eta)(1-g)-\beta^{2}(1+\eta)} .
$$

Equation (A.22) is substituted into equation (A.1). According to the existence condition of the extreme value of a multivariate function, if an extreme value exists in the expected profit function of the manufacturer, $\beta^{2}(1-i)^{2}(1+$ 
$\eta)+4 u(1-i)(1-g)(1+\eta)(i-1)-4 u \eta(1-g)(1-i)^{2}<0$ should be met. In this case, the first-order partial derivatives of $w$ and $\theta$ in equation (A.1) are solved and equalized to 0 , so the following equation is obtained:

$$
\begin{aligned}
& \frac{\partial \pi_{m}}{\partial w}=(1-i)\left(\frac{1}{2} a+\frac{1}{2} \beta \theta-i c-w+i w+\frac{1}{2} c\right)-\frac{\eta w(1-i)^{2}}{1+\eta}+\frac{\eta c(1-i)^{2}}{1+\eta}=0, \\
& \frac{\partial \pi_{m}}{\partial \theta}=\frac{1}{2} \beta(1-i)(w-c)-u \theta k=0 .
\end{aligned}
$$

By the simultaneous system of equations (A.23) and (A.24), $w^{\mathrm{III}}$ and $\theta^{\mathrm{III}}$ can be solved as follows:

$$
\begin{aligned}
w^{\mathrm{III}} & =\frac{(1+\eta)\left[2 u a(1-g)-c \beta^{2}(1-i)-4 u i c(1-g)+2 u c(1-g)\right]+4 u \eta c(1-g)(1-i)}{(1+\eta)\left[4 u(1-g)-\beta^{2}(1-i)-4 u i(1-g)\right]+4 u \eta(1-i)(1-g)}, \\
\theta^{\mathrm{III}} & =\frac{\beta(1+\eta)(a-c)}{(1+\eta)\left[4 u(1-g)-\beta^{2}\right]+4 u \eta(1-g)} .
\end{aligned}
$$

Equations (A.25) and (A.26) are substituted into equation (A.12) to solve the pricing decision of the online retailer as follows:

$$
\begin{aligned}
p^{\mathrm{III}}= & \frac{a u(3+5 \eta-3 g+4 \lambda)-\beta^{2} c(1+\lambda)(1+\eta)+c u(1+3 \eta-g)}{(1+\lambda)\left[4 u(1+2 \eta)(1-g)-\beta^{2} c(1+\lambda)\right]} \\
& +\frac{6 a \eta \lambda u(1-g)-c \eta g u(3+2 \lambda)-a g u(5 \eta+4 \lambda)}{(1+\lambda)\left[4 u(1+2 \eta)(1-g)-\beta^{2} c(1+\lambda)\right]} .
\end{aligned}
$$

Equations (A.25)-(A.27) are substituted into equations (A.1) and (A.12) to solve the manufacturer's utility and the online retailer's utility under asymmetric fairness preferences as follows:

$$
\begin{aligned}
U_{m}^{\mathrm{III}}= & \pi_{m}^{\mathrm{III}}=\frac{u(a-c)^{2}(1+\eta)(g-1)\left[\beta^{2}(1+\lambda)(1+\eta)+4 u(1+3 \eta)(g-1)+8 \eta \lambda u(g-1)\right]}{2(1+\lambda)\left[\beta^{2}(1+\eta)-4 u(1+2 \eta)(1-g)\right]} \\
U_{r}^{\mathrm{III}}= & \frac{u(a-c)\left[\beta^{2} \eta \lambda(1+\lambda)(\eta+2)-\beta^{2} \eta g\left(2 \lambda^{2}+3 \lambda+1\right)(\eta+2)+2 u\left(g^{2}-2 g+1\right)-36 u \eta^{2} g\right]}{2(1+\lambda)\left[\beta^{2}(1+\eta)-4 u(1+2 \eta)(1-g)\right]^{2}} \\
& +\frac{u(a-c)\left[-\beta^{2} g\left(2 \lambda^{2}+3 \lambda+1\right)+\beta^{2}(1+\lambda)+2 u \eta^{2}\left(4 \lambda^{2}+12 \lambda+9\right)\left(g^{2}+1\right)-16 u \eta^{2} g \lambda(\lambda+3)\right]}{2(1+\lambda)\left[\beta^{2}(1+\eta)-4 u(1+2 \eta)(1-g)\right]^{2}} \\
& +\frac{u(a-c)\left[4 u \eta(2 \lambda+3)\left(g^{2}-2 g+1\right)\right]}{2(1+\lambda)\left[\beta^{2}(1+\eta)-4 u(1+2 \eta)(1-g)\right]^{2}} .
\end{aligned}
$$




\section{B. Deduction 1 Proof}

According to equations (A.7), (A.16), and (A.25), the $(w-c)$ values under the three circumstances can be solved as follows:

$$
\begin{aligned}
& w^{\mathrm{III}}-c=\frac{2 u(c-a)(1-g)}{(1-i)\left[\beta^{2}-4 u(1-g)\right]}, \\
& w^{\mathrm{III}}-c=\frac{2 u(1-g)(a-c)(1+\lambda)}{(1-i)\left[4 u(1-g)(1+\lambda)-\beta^{2}(1+\lambda)+4 u \lambda(1-g)\right]}, \\
& w^{\mathrm{III}}-c=\frac{2 u(1-g)(a-c)(1+\eta)}{(1-i)\left[4 u(1-g)(1+\eta)-\beta^{2}(1+\eta)+4 u \eta(1-g)\right]} .
\end{aligned}
$$

Equation (A.2) is simplified into equation (B.4) as follows:

$$
\pi_{r}=(a-p+\beta \theta)[p-c-(1-i)(w-c)]-\frac{1}{2} u g \theta^{2} .
$$

According to equations (B.1)-(B.3), the single-commodity profit of the manufacturer is positively correlated with revenue sharing ratio $i$. The substitution of equations (B.1)-(B.3) into equation (A.1) shows that the manufacturer's profit is unrelated to its revenue sharing ratio $(1-i)$. The unit profit of low-carbon products increases with revenue sharing ratio $i$, but the revenue proportion held by the manufacturer itself continuously decreases with the continuous increase in the revenue shared to the online retailer. Therefore, the profit finally allocated to the manufacturer is unrelated with $i$. According to the calculation results under the three circumstances, the manufacturer's revenue sharing ratio has no bearing on the product retail price, the manufacturer's carbon emission reduction, the manufacturer's profit, or the online retailer's utility.

\section{Data Availability}

The data used to support the findings of this study titled "Pricing Problem in the E-Commerce Low-Carbon Supply Chain under Asymmetric Fairness Preferences" are included within the article.

\section{Conflicts of Interest}

The authors declare that they have no conflicts of interest.

\section{References}

[1] D. Ghosh and J. Shah, "Supply chain analysis under green sensitive consumer demand and cost sharing contract," International Journal of Production Economics, vol. 164, pp. 319-329, 2015.

[2] Z. Liu, X.-X. Zheng, B.-G. Gong, and Y.-M. Gui, "Joint decision-making and the coordination of a sustainable supply chain in the context of carbon tax regulation and fairness concerns," International Journal of Environmental Research and Public Health, vol. 14, no. 12, p. 1464, 2017.

[3] H. S. Chan, S. Li, and F. Zhang, "Firm competitiveness and the European Union emissions trading scheme, Energy Policy," Social Science Electronic Publishing, vol. 63, pp. 1056-1064, 2013.

[4] Z. Wang and C. Wang, "How carbon offsetting scheme impacts the duopoly output in production and abatement: analysis in the context of carbon cap-and-trade," Journal of Cleaner Production, vol. 103, pp. 715-723, 2015.

[5] S.-S. Li and Y. He, "Compensation and information disclosure strategies of a green supply chain under production disruption," Journal of Cleaner Production, vol. 281, no. 1, pp. 50-55, 2020.

[6] M. E. Drumwright, "Socially responsible organizational buying: environmental concern as a noneconomic buying criterion," Journal of Marketing, vol. 58, no. 3, pp. 1-19, 1994.

[7] K. Shimokawa, Japan and the Global Automotive Industry, Cambridge University Press, Cambridge, UK, 2010.

[8] Y. He, H. Song, and P. Zhang, Optimal Selling Strategy in Dual-Channel Supply Chains, Springer Berlin Heidelberg, Berlin, Germany, pp. 247-252, 2013.

[9] Z.-Y. Zhang, D.-X. Fu, and Q. Zhou, "Optimal decisions of a green supply chain under the joint action of fairness preference and subsidy to the manufacturer," Discrete Dynamics in Nature and Society, vol. 10, no. 4, pp. 285-290, 2020.

[10] Y.-Y. Wang, Z.-Q. Yu, M.-Z. Jin, and J.-F. Mao, "Decisions and coordination of retailer-led low-carbon supply chain under altruistic preference," European Journal of Operational Research, vol. 12, no. 6, pp. 36-45, 2021.

[11] L.-C. Sun, X.-X. Cao, M. Alharthi, J.-J. Zhang, T. Farhad, and M. Mohsin, "Carbon emission transfer strategies in supply chain with lag time of emission reduction technologies and low-carbon preference of consumers," Journal of Cleaner Production, vol. 15, no. 3, pp. 264-271, 2020.

[12] R.-G. Fan, J.-C. Lin, and K.-W. Zhu, "Study of game models and the complex dynamics of a low-carbon supply chain with an altruistic retailer under consumers' low-carbon preference," Physica A: Statistical Mechanics and Its Applications, vol. 10, no. 4, pp. 12-24, 2019.

[13] Q.-F. Meng, M.-G. Li, W.-Y. Liu, Z. Li, and J. Zhang, "Pricing policies of dual-channel green supply chain: considering government subsidies and consumers' dual preferences," Sustainable Production and Consumption, vol. 3, no. 8, pp. 126-135, 2021. 
[14] S. Du, J. Zhu, H. Jiao, and W. Ye, "Game-theoretical analysis for supply chain with consumer preference to low carbon," International Journal of Production Research, vol. 53, no. 12, pp. 3753-3768, 2015.

[15] Y. Li and D.-Z. Zhao, "Research on contract coordination of a low-carbon supply chain considering fair preference," Journal of Management in Engineering, vol. 29, no. 1, pp. 156-161, 2015.

[16] Q. Li, X. Chen, and Y. Huang, "The stability and complexity analysis of a low-carbon supply chain considering fairness concern behavior and sales service," International Journal of Environmental Research and Public Health, vol. 16, no. 15, p. 2711, 2019.

[17] H. Zou, J. Qin, and B. Dai, "Optimal pricing decisions for a low-carbon supply chain considering fairness concern under carbon quota policy," International Journal of Environmental Research and Public Health, vol. 18, no. 2, p. 556, 2019.

[18] D. Z. Zhao, C. Q. Xu, and Q. P. Wang, "Differential strategies of joint emission reductions and low-carbon promotion considering competing retailers," Control and Decision, vol. 29, no. 10, pp. 1809-1815, 2014.

[19] Q. Wang, D. Zhao, and L. He, "Contracting emission reduction for supply chains considering market low-carbon preference," Journal of Cleaner Production, vol. 120, pp. 7284, 2016.

[20] S. Huang, F. Xu, and J. He, "Cooperative reduction and promotion decision model in dual channel supply chain," Science and Technology Management Research, vol. 37, pp. 246-256, 2017.

[21] H. Li and C. Wang, "Closed loop supply chain enterprise cooperative carbon emission decisions with carbon emission constraints," Computer Engineering and Applications, vol. 54, no. 12, 2018.

[22] E. Fehr and K. M. Schmidt, "A-theory of fairness, competition, and cooperation," Quarterly Journal of Economics, vol. 114, no. 3, pp. 817-868, 1999.

[23] T. Haitao Cui, J. S. Raju, and Z. J. Zhang, "Fairness and channel coordination," Management Science, vol. 53, no. 8, pp. 1303-1314, 2007.

[24] C. H. Loch and Y. Wu, "Social preferences and supply chain performance: an experimental study," Management Science, vol. 54, no. 11, pp. 1835-1849, 2008.

[25] O. Caliskan-Demirag, Y. Chen, and J. Li, "Channel coordination under fairness concerns and nonlinear demand," European Journal of Operational Research, vol. 207, no. 3, pp. 1321-1326, 2010.

[26] S. Du, T. Nie, C. Chu, and Y. Yu, "Newsvendor model for a dyadic supply chain with Nash bargaining fairness concerns," International Journal of Production Research, vol. 52, no. 17, pp. 5070-5085, 2014.

[27] Y. Zhou, M. Bao, X. Chen, and X. Xu, "Co-op advertising and emission reduction cost sharing contracts and coordination in low-carbon supply chain based on fairness concerns," Journal of Cleaner Production, vol. 133, pp. 402-413, 2016.

[28] L. Zhang, B. Xue, and X. Liu, "Carbon emission reduction with regard to retailer's fairness concern and subsidies," Sustainability, vol. 10, no. 4, p. 1209, 2018.

[29] Q. Li, M. Shi, and Y. Huang, "A dynamic price game model in a low-carbon, closed-loop supply chain considering return rates and fairness concern behaviors," International Journal of Environmental Research and Public Health, vol. 16, no. 11, Article ID 1978, 2019.

[30] L.-F. Dai, X.-F. Wang, X.-G. Liu, L. Wei, and A. Sensoy, "Pricing Strategies in Dual-Channel Supply Chain with a Fair
Caring Retailer," Complexity, vol. 2019, Article ID 1484372, 23 pages, 2019.

[31] E.-B. Cao and L.-M. Hou, "Research on the optimal decision of supply chain in asymmetry of fairness concern," Chinese Journal of Management, vol. 13, no. 7, pp. 1070-1074, 2016.

[32] X.-H. Wu, X.-Z. Ai, and J.-J. Nie, "The impact of asymmetric fairness concern on low carbon supply chain decisions," Journal of Central University of Finance \& Economics, vol. 390, no. 2, pp. 96-128, 2020.

[33] S. Swami and J. Shah, "Channel coordination in green supply chain management," Journal of the Operational Research Society, vol. 64, no. 3, pp. 336-351, 2013.

[34] D. Ghosh and J. Shah, "A comparative analysis of greening policies across supply chain structures," International Journal of Production Economics, vol. 135, no. 2, pp. 568-583, 2011.

[35] I. Biswas, A. Raj, and S. K. Srivastava, "Supply chain channel coordination with triple bottom line approach," Transportation Research Part E: Logistics and Transportation Review, vol. 115, pp. 213-226, 2018.

[36] T. Nie and S. Du, "Dual-fairness supply chain with quantity discount contracts," European Journal of Operational Research, vol. 258, no. 2, pp. 491-500, 2017.

[37] E. Katok, T. Olsen, and V. Pavlov, "Wholesale pricing under mild and privately known concerns for fairness," Production and Operations Management, vol. 23, no. 2, pp. 285-302, 2014. 